\title{
Modelling Complex Insect Invasions: European House Borer as a case study
}

\author{
$\underline{\text { O.J. Cacho }}^{\text {a }}$, S.M. Hester ${ }^{\text {ab }}$ \\ ${ }^{a}$ UNE Business School, University of New England, Armidale NSW 2351, Australia \\ ${ }^{b}$ Centre of Excellence for Biosecurity Risk Analysis (CEBRA), The University of Melbourne, Parkville, VIC \\ 3010 \\ Email: ocacho@une.edu.au
}

\begin{abstract}
The European House Borer (EHB) is a serious insect pest of untreated dry softwood. The adult beetle lays its eggs into cracks and holes in the deadwood, with larvae subsequently hatching from the eggs and causing damage by feeding on the timber. Serious structural damage can occur when found in timber in buildings. Traditional optimisation models of invasions are of limited applicability for EHB because this pest not only infests the dead parts of pine trees in forests, it also infests buildings. Pine forests are the main habitat of EHB but the damage occurs mostly in residential areas. This means that knowledge of the extent of the invasion (infested area) does not provide enough information to describe the state of the system for management purposes. Another complication is that control of the invasion involves "packages" of actions. These actions cannot be easily related to reductions in area invaded as continuous variables.
\end{abstract}

A three-state variable model was developed to represent the problem. A number of parameters need to be estimated to represent the spread and management of the invasion, but the data needed for direct estimation are not available. We developed a numerical model that derives time trajectories of forest area, houses at risk and number of infested houses for any combination of parameter values and control packages. The four available control options within each package are building restrictions within restricted movement zones; early harvest of softwood plantations; forest hygiene activities; and fixed-cost activities associated with the EHB management programme. A full factorial design was used to test the effects of all possible combinations of control options. All the control packages result in a gradual reduction of the infestation. Under the base assumptions any form of control is preferred to no control. The present value of total cost is around \$7 billion under no control and $\$ 800$ million under full control.

The tool developed in this research may be used by biosecurity agencies to estimate plausible parameters sets based on their experience and considering the population dynamics of the EHB. The model can be used in an iterative approach to guide further data collection and should be applicable to other pests with similar spread and impact characteristics.

Keywords: $\quad$ Biosecurity, European House Borer, dynamic models, model calibration, invasive species 


\section{INTRODUCTION}

Invasive insect pests can have devastating economic, social and environmental consequences in regions where they establish (Aukema et al. 2011). Effective management of insect pests requires a basic understanding of spatial and temporal spread patterns in an environment of significant uncertainty about past and future spread. Understanding the invasion process using spread models has proved particularly useful in formulating effective management strategies (Yemshanov et al. 2009; Cacho et al. 2010; Epanchin-Niell and Liebhold 2015; Mercarder et al. 2011; Kovacs et al. 2014).

Modelling the spread of insect pests, however, is not always straightforward, particularly when the habitat of the pest is not where the damage occurs. In these cases, knowledge of the extent of the invasion (infested area) does not provide enough information to describe the state of the system for management purposes. This is the case with European House Borer (EHB) (Hylotrupes bajulus), a serious insect pest of untreated dry softwood, including, pine, fir and spruce. EHB is native to Europe, but is now found in South Africa, Asia, USA and Canada, becoming a serious pest of seasoned softwood timbers in all countries where it has become established. In Western Australia, the pest has been found in dead pinewood or the dead parts of live pine trees (dried out branch stubs, damaged branches and trunks), dead trees and logs, and untreated manufactured articles derived from pine timber (DAFWA 2010). The adult beetle lays its eggs into cracks and holes in the deadwood, with larvae subsequently hatching from the eggs and causing damage by feeding on the timber. When found in timber in buildings, serious structural damage can occur after 2-3 generations have infested the same piece of wood.

Natural spread of EHB is slow - the pest can live in its larval state for 2-12 years before it matures and emerges from the timber as an adult beetle, to begin the life cycle again (DAFWA 2008a). An adult EHB beetle usually travels only a minimal distance if its food source has not yet been exhausted, which can take more than 10 years (DAFWA 2010). While it is possible for migrating beetles to fly and be dispersed by winds, there is also great potential for EHB to be spread large distances by human-assisted transport of infested pine wood.

An incursion of EHB was detected in Western Australia in January 2004 in a private residence - it is thought that EHB had been in the infested areas for 15 to 30 years prior to detection (Blanchard et al. 2006). When subsequent surveillance uncovered EHB at 27 properties in 10 Perth suburbs the State Government began an emergency response plan. The response programme involved a mix of surveillance, regulations on the movement of untreated pinewood, research and education activities. By September 2010, there were 178 EHB infested sites across 50 suburbs in the greater Perth metropolitan area and one infested site in Albany (DAFWA 2010). While most infestations have been found in pine waste material and dead parts of live pine trees, the pest has been found in structural material in a home which is thought to have become infested after EHB dispersed from nearby pine trees. Other infestations in structural materials have occurred but timber was found to be infested prior to installation in homes.

In 2006 the State Government introduced the Agriculture and Related Resources Protection (European House Borer) Regulations 2006. The regulations restrict the movement, storage, treatment and disposal of untreated pinewood within EHB affected areas, known as Restricted Movement Zones (RMZs). According to DAFWA, assistance from individuals and businesses in complying with these regulations has played a large role in reducing the spread and infestation of EHB.

This paper describes a dynamic model of the EHB incursion based on three state variables. Given that the data needed for direct estimation of parameters were not available, we show how the model can be used both to estimate parameters and to assist with planning management of the invasion.

\section{THE MATHEMATICAL MODEL}

The European House Borer problem has features that require several interrelated state variables to be introduced (Figure 1). The state of the infestation at any time is described by the number of houses infested $\left(y_{t}\right)$, the number of houses at risk $\left(h_{t}\right)$ and the area of forest infested $\left(x_{t}\right)$. Cross infection may occur from forest to houses $\left(m_{x}\right)$ and from houses to forests $\left(m_{h}\right)$. The risk of cross infection will depend on proximity between forests and houses. The total area of forest $\left(\theta_{x}\right)$ changes through time depending of the rates of forest planting $\left(\gamma_{\text {plant }}\right)$ and harvesting $\left(\gamma_{\text {harvest }}\right)$. The number of susceptible houses changes through time depending on the rate at which new houses are built using untreated softwood $\left(\gamma_{\text {new }}\right)$, and the rate at which existing susceptible houses are protected $\left(\gamma_{\text {prot }}\right)$ through timber replacement. 


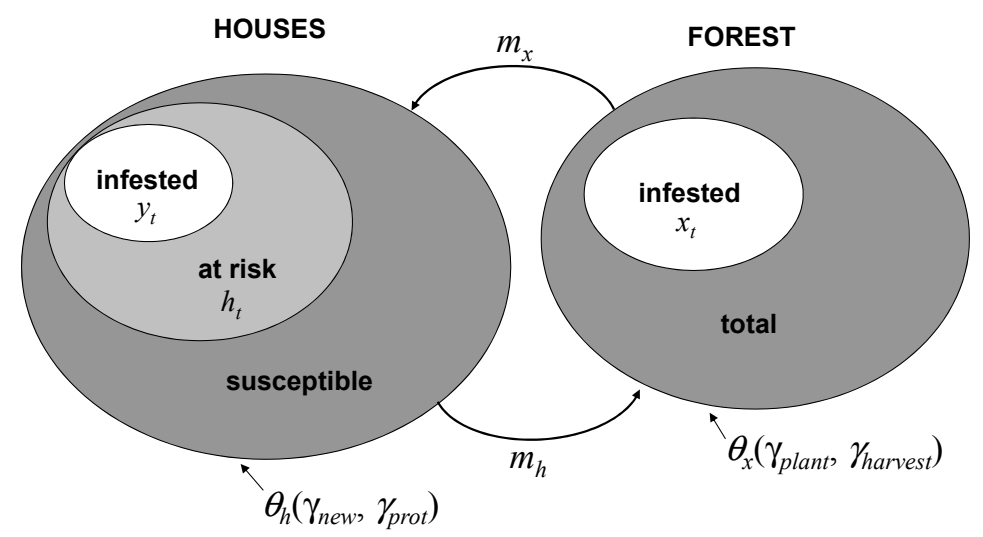

Figure 1. Diagrammatic representation of the state variables in the EHB model.

The present value of the total cost of the infestation for a planning period of $T$ years is:

$$
\left.P V C(T)=\sum_{t=1}^{T}\left[C_{t}\left(x_{t}, h_{t}, \mathbf{u}_{t}\right)+D_{t}\left(x_{t}, h_{t}, y_{t}, \mathbf{u}_{t}\right)\right)\right](1+\delta)^{-t}
$$

Where Annual costs $(C)$ and damages $(D)$ are functions of the three state variables $\left(x_{t}, h_{t}\right.$ and $\left.y_{t}\right)$ and a control vector $\mathbf{u}_{\mathrm{t}}$; and $\delta$ is the discount rate. The control variables contained in vector $\mathbf{u}_{t}$ are:

$$
\begin{aligned}
& u_{1}=\text { building restrictions within area at risk } \\
& u_{2}=\text { early harvest of softwood plantations } \\
& u_{3}=\text { forest hygiene activities } \\
& u_{4}=\text { house protection (timber replacement) }
\end{aligned}
$$

The changes of $x_{t}, h_{t}$ and $y_{t}$ through time are described by state transition equations, one equation per variable:

$$
\begin{aligned}
& x_{t+1}-x_{t}=f_{x}\left(x_{t}, h_{t}\right)-g_{x}\left(\mathbf{u}_{t}\right) \\
& h_{t+1}-h_{t}=f_{h}\left(x_{t}, h_{t}\right)-g_{h}\left(\mathbf{u}_{t}\right) \\
& y_{t+1}-y_{t}=f_{y}\left(h_{t}\right)-g_{y} \\
& x_{0}, h_{0}, y_{0} \text { given }
\end{aligned}
$$

The growth rates of the state variables are given by:

$$
\begin{aligned}
& f_{x}=\alpha_{x} x_{t}\left(1-\frac{x_{t}}{\theta_{x}}\right) m_{h} \rho_{x} \\
& f_{h}=\alpha_{h} h_{t}\left(1-\frac{h_{t}}{\theta_{h}}\right) m_{x} \rho_{h} \\
& f_{y}=\alpha_{y} h_{t} m_{y} \rho_{y}
\end{aligned}
$$

Where $\alpha_{i}$ and $\rho_{i}$ are growth rates and random disturbances, respectively, for $i=x, h$, or $y$; $\theta_{x}$ is the total area of softwood forests; $\theta_{h}$ is the total number of susceptible houses; and $m_{x}, m_{h}$ and $m_{y}$ are multipliers that account for risk of cross infestation between forests and houses. Equations (5) and (6) are standard logistic growth functions that are subject to random variation and scaled based on cross-infestation risk. Equation (7) differs from others, as the growth parameter $\left(\alpha_{y}\right)$ represents the fraction of houses at risk that will become infested at saturation (when $h_{t}=\theta_{h}$ ).

We have no information on the shape of the cross-infection risk multiplier functions. We assume plausible monotonically increasing nonlinear functions to make the model operational:

$$
\begin{aligned}
& m_{h}=h^{\mu_{h}} \\
& m_{x}=x^{\mu_{x}}
\end{aligned}
$$




$$
m_{y}=\left(\frac{h_{t}}{\theta_{h}}\right)^{\mu_{y}}
$$

with $\mu_{h}, \mu_{x}, \mu_{y}>0$.

The functional forms of (8) and (9) imply that the multiplier $m_{i}=1$ when its corresponding state variable $i=1$. A better understanding of the risk of cross-infection is required to refine these relationships. Equation (10) implies that the probability of a house within the area at risk becoming infested $\left(m_{y}\right)$ increases as the proportion of susceptible houses that are at risk increases. This is also an arbitrary but plausible function.

The control functions from (5), (6) and (7) are:

$$
\begin{aligned}
& g_{x}=u_{2} \gamma_{\text {harv }} x_{t}+u_{3} \gamma_{\text {hyg }} x_{t} \\
& g_{h}=u_{4} \gamma_{\text {prot }} h_{t}+\left(1-u_{4}\right) \gamma_{\text {repair }} y_{t} \\
& g_{y}=\left(1-u_{4}\right) \gamma_{\text {repair }} y_{t}+u_{4} \gamma_{\text {prot }} y_{t}
\end{aligned}
$$

Where $\gamma_{\text {har }}$ is the fraction of forest area that is harvested per year, $\gamma_{\text {hyg }}$ is the fraction of forest that is subject to hygiene activities (clearing of dead wood) and $\gamma_{\text {prot }}$ is the fraction of houses at risk that becomes protected from infestation because of roof/timber replacement.

The cost function applies when a control program exists and is defined as:

$$
C_{t}=u_{1} \gamma_{\text {new }} C_{\text {restrict }} h_{t}+u_{2} \gamma_{\text {harv }} C_{\text {harv }} x_{t}+u_{3} \gamma_{\text {hyg }} C_{\text {hyg }} x_{t}+u_{4} C_{\text {fix }}
$$

The components of this equation in order of appearance are:

- the cost of building restrictions in the area at risk;

- the cost of early forest harvest;

- the cost of forest hygiene; and

- fixed program costs.

The damage function is:

$$
\begin{aligned}
& D_{t}=\left(1-u_{1}\right) \gamma_{\text {new }} C_{\text {restrict }} \theta_{h}+C_{\text {inspect }} h_{t}+\gamma_{\text {prot }} C_{\text {prot }} h_{t}+ \\
& C_{\text {Vloss }} h_{t}+C_{\text {pub }} h_{t}+\left(1-u_{4}\right) \gamma_{\text {repair }} C_{\text {prot }} y_{t}+\left(1-u_{4}\right) C_{\text {pallet }}
\end{aligned}
$$

The components of this equation in order of appearance are:

- the cost of building restrictions throughout WA, which means the stock of susceptible houses will not be allowed to grow (this would apply if a control program does not exist);

- the cost of house inspections in the area at risk;

- the cost of house protection by replacing softwood in the area at risk;

- the loss of land value within the area at risk;

- the cost of damage to public property within the area at risk;

- the cost of repairing infested houses when a control program does not exist;

- the cost of replacing pallets for interstate trade when a control program does not exist.

The cost and damage parameters are:

$C_{\text {restrict: }}$ the cost of building restrictions (\$/house) measured as the additional of building a nonsusceptible house.

$C_{\text {harv }}$ : the cost of early harvest of pine plantations ( $\$$ ha infested)

$C_{h y g}$ t the cost of increased forest hygiene and clean-up of affected areas

$C_{f i x}$ : fixed annual costs (admin etc) $(\$ / y r)$

$C_{\text {inspect }}$ cost of annual house inspections $(\$ / \mathrm{hh})$

$C_{\text {prot: }}$ cost of protecting houses through timber replacement $(\$ / \mathrm{hh})$

$C_{\text {vloss: }}:$ loss in property value for houses located within are at risk $(\$ / \mathrm{hh})$

$C_{p u b}$ : cost of fixing and protecting public infrastructure, such as hospitals, school and halls, in area at risk $(\$ / \mathrm{hh})$

$C_{\text {pallet: }}$ cost of treating pallets $(\$ /$ pallet) 
One of the largest damages comes from the impact of an EHB incursion on interstate trade - all softwood leaving WA would need to be treated to allow entry into other Australian states and territories. The value of the damage appears largest for softwood pallets that are commonly used in transportation of goods. A number of these pallets would need to be permanently treated at a cost of $C_{\text {pallet }}(\$ / y r)$ for use in interstate trade.

Finally, actions by the public and government will affect the maximum areas at risk $\theta_{i}$. The amount of forest will change depending on the rate of harvest relative to the rate of replanting:

$$
\theta_{x}=\left(1+\gamma_{\text {plant }}-u_{2} \gamma_{\text {harv }}\right) \theta_{x}
$$

The maximum number of susceptible houses will change depending on the number of new houses built with untreated pine, the number of existing houses that become protected, and the number of infested houses that are repaired.

$$
\theta_{h}=\theta_{h}+u_{1} \gamma_{\text {new }}\left(\theta_{h}-h_{t}\right)-u_{4} \gamma_{\text {prot }} h_{t}-\left(1-u_{4}\right) \gamma_{\text {repair }} y_{t}
$$

\section{THE NUMERICAL EHB MODEL}

Numerical implementation of the EHB model requires estimates of several parameters. Ideally these estimates should come from actual data, but unfortunately very limited data were available in useable form. To overcome this limitation we use the EHB model to estimate parameter values through trial and error. This allows an iterative approach to be established

\subsection{Model Description}

In summary, the model accounts for three state variables and uses discrete control actions. The main output of the model is the total cost of the invasion (TC), defined as the sum of the damages caused by the invasion plus the costs of managing it, in present-value terms. Most damages occur in residential areas and hence depend on the number of houses at risk and houses infested. These include costs of additional pest inspections required within the area at risk; the cost of protecting existing houses at risk; possible loss in property values and costs of repairing infested public buildings. In addition to these property damages, the transportation industry faces the cost of treating pallets and crates used for interstate trade.

The value of $T C$ depends on the time trajectory of three state variables and a control variable. The state variables are the number of houses infested $\left(y_{t}\right)$, the number of houses at risk $\left(h_{t}\right)$ and the area of forest infested $\left(x_{t}\right)$. The control variable $\left(u_{t}\right)$ is a binary string of four digits representing a given package of control options. The control options are: (1) building restrictions within RMZ; (2) early harvest of softwood plantations; (3) forest hygiene activities; (4) fixed-cost activities.

An option is turned on or off by setting its value to 1 or 0 in the appropriate position within $\mathbf{u}_{t}$. For example $\mathbf{u}_{t}$ $=[0,0,0,0]$ represents no control and $\mathbf{u}_{t}=[1,0,0,1]$ represents a situation with building restrictions but no early harvest or forest hygiene. In the latter case the final digit is set to 1 to account for the fixed annual costs of running the programme.

The EHB Excel model performs the numerical solution of the mathematical model described above. It simulates the three state variables $\left(x_{t}, h_{t}\right.$ and $\left.y_{t}\right)$ forward in time based on the control $\mathbf{u}_{t}$ applied. The management strategy (the 4 entries contained in $\mathbf{u}_{t}$ ) is kept fixed within a simulation run. This is a deterministic model and does not perform optimisation, but allows the user to explore alternative control scenarios. The model is designed to allow managers to compare the consequences of alternative actions. The numerical model is written in Visual Basic within Excel. The user can modify parameter values and click the 'Run' button to solve the model and evaluate whether any given parameter combination makes sense (Figure 2).

\subsection{Using the Model}

The EHB model can be used to investigate a number of scenarios (Table 1), including the option of no control $\left(\mathbf{u}_{t}=[0,0,0,0]\right)$ and full control $\left(\mathbf{u}_{t}=[1,1,1,1]\right)$. Model parameters values were obtained from a range of sources: the cost-benefit analysis of EHB management options and detailed bioeconomic model undertaken by Blanchard et al. (2006); the Regulatory Impact Statement on Building Regulations for European House Borer (The Allen
Table 1. Control packages tested with the model.

\begin{tabular}{ccccc}
\hline & \multicolumn{4}{c}{ Control actions } \\
\cline { 2 - 5 } $\begin{array}{c}\text { Treatment } \\
\text { package }\end{array}$ & $\begin{array}{c}\text { 1. Building } \\
\text { restrictions }\end{array}$ & $\begin{array}{c}\text { 2. Early } \\
\text { harvest }\end{array}$ & $\begin{array}{c}\text { 3. Forest } \\
\text { hygiene }\end{array}$ & $\begin{array}{c}\text { 4. Fixed } \\
\text { programme } \\
\text { costs }\end{array}$ \\
\hline A & 0 & 0 & 0 & 0 \\
B & 1 & 0 & 0 & 1 \\
C & 0 & 1 & 0 & 1 \\
D & 1 & 1 & 0 & 1 \\
E & 0 & 0 & 1 & 1 \\
F & 1 & 0 & 1 & 1 \\
G & 0 & 1 & 1 & 1 \\
H & 1 & 1 & 1 & 1 \\
\hline
\end{tabular}




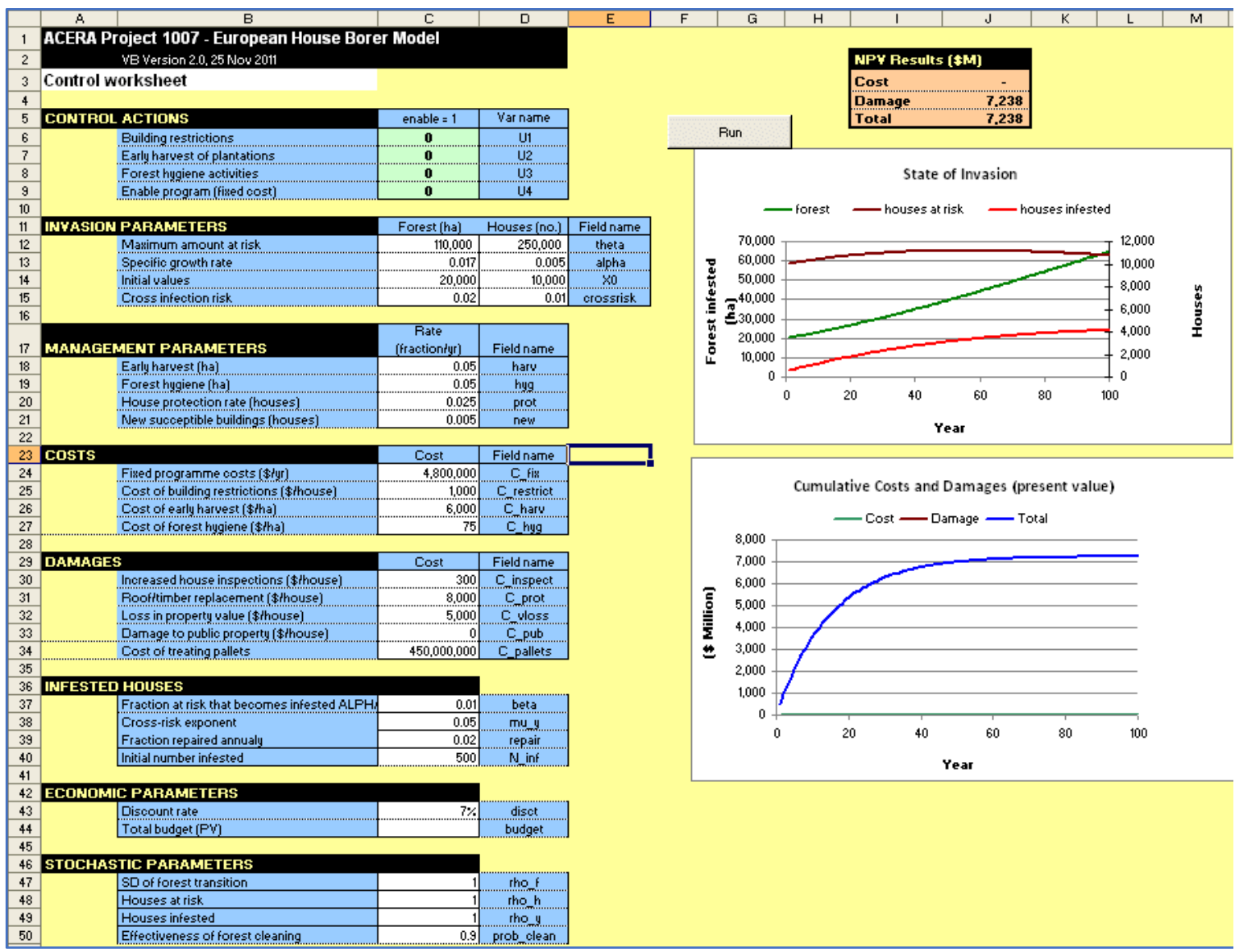

Figure 2. The EHB numerical model for a set of arbitrary parameter values. The total budget and stochastic parameters are not used by this version of the model.

Consulting Group 2006) and personal communication with members of the EHB eradication team. Where no information was available we used hypothetical but plausible values.

\section{RESULTS}

Under the no-control scenario (Figure 3a) the forest area infested continues to grow throughout the 100 years simulated. The stock of houses at risk stabilises and then decreases slightly as susceptible houses are protected at private expense. The number of infested houses continues to increase throughout the 100 years but at a decreasing rate as number of houses at risk stabilises. Under the full control scenario (Figure $3 b$ ) forest area infested and houses at risk decrease rapidly as control actions and building restrictions are implemented. The number of houses infested increases for about 40 years before starting to decrease in response to the control actions. Other control packages result in intermediate results, but all the control packages result in a gradual reduction of the infestation (not shown).Under the base assumptions any form of control is preferred to no control. The present value of total cost (damages plus control costs over 100 years) is around $\$ 7$ billion under no control and $\$ 800$ million under full control. These results are roughly consistent with the benefit cost

(a) 0000

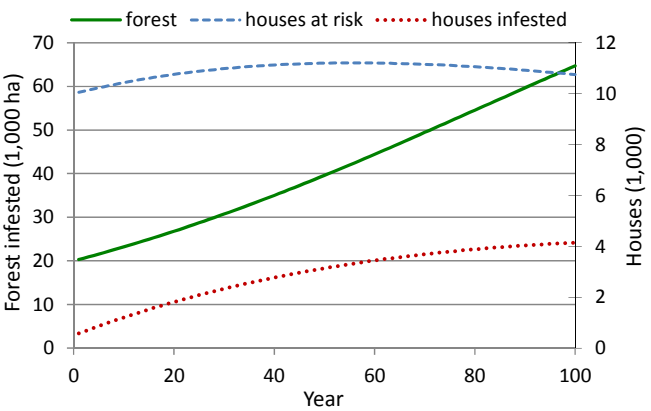

(b) 1111

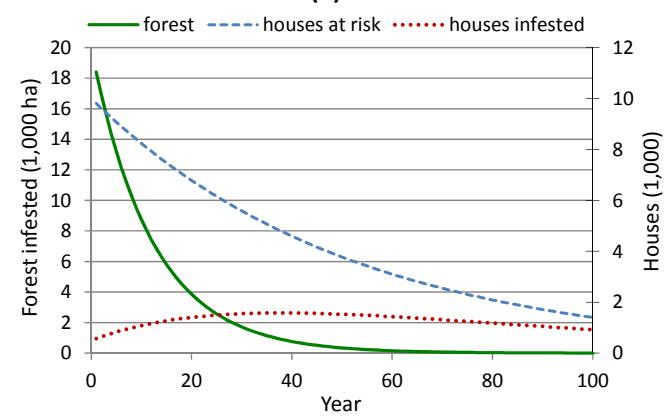

Figure 3. Simulated trajectory of the three state variables under no control (a) and full control (b). 
analysis of Blanchard et al. (2006). Further work should focus on refining parameter values and finding realistic rates of control based on skills and budgets available.

\section{DISCUSSION AND CONCLUSIONS}

Our findings indicate that any form of control of the current outbreak is preferable to no control at all, based on the damages to Western Australia relative to the cost of control. This result is based on a combination of best estimates available and plausible values for unknown parameters due to the difficulty in deriving some of them. As management of EHB in WA continues more data is becoming available to parameterise the model. Pending data availability, tool presented in this work could be modified for the range of insect pests with the same invasive pattern as EHB.

At a more general level, the difficulty of extracting data, even when they exist in internal databases, needs to be addressed. This is a common problem in public agencies, caused by the limited availability of staff with the required skills to manage and extract spatio-temporal data. This can be addressed by developing protocols for data sharing that account for security concerns while at the same time allowing data access to teams with the skills needed to make the best out of the information available.

\section{ACKNOWLEDGMENTS}

Funding for this research was provided by the Centre of Excellence for Biosecurity Risk Analysis (CEBRA) through Project 1004C. Assistance from the EHB team at DAFWA is gratefully acknowledged.

\section{REFERENCES}

Aukema, J.E., Leung, B., Kovacs, K., Chivers, C., Britton, K.O., Englin, J., Frankel, S.J., Haight, R.G., Holmes, T.P., Liebhold, A.M., McCullough, D.G., and B. Von Holle (2011). Economic impacts of nonnative forest insects in the continental United States. PLoS ONE, 6(9), e24587. doi:10.1371/journal.pone.0024587.

Blanchard, R., Edward, A., Evans, L. and Kingwell, R. (2006). Cost Benefit Analysis of European House Borer management Options: Preliminary Findings.

Cacho, O.J., Spring, D., Hester, S.M. and R. Mac Nally, R (2010). Allocating surveillance effort in the management of invasive species: a spatially-explicit model. Environmental Modelling and Software, 25(4), 444-454.

DAFWA Department of Agriculture and Food of Western Australia (2008a). About EHB: http://www.ehb.wa.gov.au/html/about01_intro.htm

DAFWA (2008b). EHB Response Program, http://www.ehb.wa.gov.au/html/about04_ehbprogram.htm

DAFWA (2008c). EHB: New Proposed Industry Regulations. http://www.ehb.wa.gov.au/html/newregs.htm

DAFWA (2010). European House Borer: Fact Sheet, http://www.ehb.wa.gov.au/factsheets/EHB_fact_sheet_April_2010.pdf

Epanchin-Neill, R.S. and A.M. Liebhold (2015). Benefits of invasion prevention: effect of time lags, spread rates, and damage persistence. Ecological Economics, 116, 146-153.

Kovacs, R.G., Haight, R.G., Mercader, R.J. and Deborah G. McCullough (2014). A bioeconomic analysis of an emerald ash borer invasion of an urban forest with multiple jurisdictions. Resource and Energy Economics, 36, 270-289.

Mercarder, R.J., Siegert, N.W., Liebhold, A.M., and D.G. McCullogh (2011). Simulating the effectiveness of three potential management options to slow the spread of emerald ash borer (Agrilus planipennis) populations in localized outlier sites. Canadian Journal of Forestry Research, 41, 254-264.

The Allen Consulting Group (2006). Building Regulations for European House Borer, Draft Regulatory Impact Statement, Confidential Report to the Department of Housing and Works.26p.Lee, S.Y., Dunn, R.J.K., and Young, R.A. (2006). Impact of urbanization on coastal wetland structure and function. Austral Ecology, 31, 149-163.

Yemshanov, D., Kovacs, K.F., Haight, R.G., Mercader, R.J., and D G. McCullough (2009). A bioeconomic approach to assess the impact of an alien invasive insect on timber supply and harvesting: a case study with Sirex nocilio in eastern Canada. Canadian Journal of Forestry Research, 39 154-168. 